\title{
Effectiveness of toughened glassware in terms of reducing injury in bars: a randomised controlled trial
}

Alison L Warburton, Jonathan P Shepherd

\begin{abstract}
Objective-To evaluate the effectiveness, in terms of injury prevention, of toughened pint glassware in bars.

Design-Randomised controlled trial. Setting-A random sample of 57 bars in South Wales, West Midlands, and West of England.

Subjects-A total of 1229 bar workers. Intervention-Complete replacement of pint glasses with annealed (control) or toughened (intervention) glassware.

Main outcome measures-Bar staff injuries recorded monthly: number, site, and severity (lifestyle impact; treatment need) of injuries.

Results-Ninety eight bar staff experienced 115 injuries: 43 in the control group, 72 in the intervention group. Adjusting for people at risk gave a relative risk (RR) of 1.48 (confidence interval (CI) 1.02 to 2.15). Similarly, adjusting for hours worked gave RR 1.57 (CI 1.08 to 2.29). Thus, injury rate was $60 \%$ higher in the intervention group $(p<0.05)$, with no significant difference in severity. Most were hand injuries requiring first aid. Injuries tended to occur simultaneously in more than one body part in the intervention group, reportedly caused by spontaneous disintegration of toughened glassware. Impact resistance testing showed the energy required to break annealed glass $(1.8 \pm 0.2 \mathrm{~J})$ was greater than that for toughened glass $(1.4 \pm 0.2 \mathrm{~J})$, though the difference was not significant.

Conclusions-Glass with lower impact resistance caused more injuries. "Toughened" glassware had lower impact resistance. Standards for toughening need to be developed.

(Injury Prevention 2000;6:36-40)
\end{abstract}

Keywords: toughened glass; bar workers; quality control

Violence Research Group, Department of Oral Surgery Medicine and Pathology, Dental School, University of Wales College of Medicine, Heath Park, Cardiff CF14 4XY, UK A L Warburton J P Shepherd

Correspondence to: Professor Shepherd, Professor of Oral and Maxillofacial Surgery
Bar glassware is responsible for about $10 \%$ of assault injuries that present to UK emergency units $^{12}$ and these usually lead to permanent, disfiguring facial scars. ${ }^{3}$ In $75 \%$ of cases, the one pint "Nonic" glass has been implicated. ${ }^{3}$ The Nonic is a straight sided one pint glass with a bulbous portion towards the rim. Toughened glass is produced by a process that involves rapid cooling of the glass after its initial formation, thereby producing a compressive outer skin that holds the outer layer together. Because all glass tends to break at the site of microcracks and flaws, toughening prevents breakage in the outer layer by holding together such flaws and preventing their propagation. In contrast, annealed glass is cooled slowly to eliminate all internal stresses, and propagation of flaws and cracks is more likely.

Shepherd et al demonstrated two important advantages of toughened bar glassware. ${ }^{4}$ First, new toughened glasses were six times more impact resistant than annealed glasses of the same design. Second, when toughened glasses did fail they tended to disintegrate into small "sugar lump" cubes, similar to those resulting from failure of a toughened car windscreen. In addition, toughened glasses were twice as impact resistant than annealed glasses after being subject to simulated wear and tear. However, manufacturers of non-toughened glassware have claimed that spontaneous disintegration of toughened glassware can cause injury. ${ }^{5}$

These findings have led, according to the industry, to a switch from annealed to toughened glassware in UK bars licensed to sell alcohol. This has been on the assumption that toughened glassware reduces the likelihood of assault injury. However, to date, toughened bar glassware has not been subject to field trials to determine whether its use does prevent injury, both intentional and unintentional.

Unfortunately, reliable and quantifiable data on assault injury in bars is not available, but by focusing on occupational injuries incurred by bar staff it is possible to measure the effectiveness of toughened glass in terms of reducing unintentional injury.

Bar workers often sustain cuts from bar glassware, many of which involve deep structures such as ligaments, and are disabling. ${ }^{6}$ A study on the risk of occupational glass injury in bar staff revealed that $41 \%$ of bar workers in South Wales have sustained bar glass injury. ${ }^{7}$ Fifteen per cent of these had sustained five or more separate "sharp" injuries from broken glassware. After $13 \%$ of incidents, treatment had been sought in an emergency unit. Another study found that $74 \%$ of bar staff reported lacerations from broken glassware at work, and of these, $18 \%$ were injured on more than 10 occasions. ${ }^{8}$ In addition, most of those questioned had had some contact with body fluids such as blood, vomit, urine, and faeces, increasing the risk of hepatitis B. ${ }^{8}$ Straight sided one pint glasses were responsible for two thirds of all injuries, usually during stacking and washing.

Taken together this evidence suggests that replacement of annealed bar glassware with toughened glassware reduces the risks of injury, both unintentional and intentional (see 


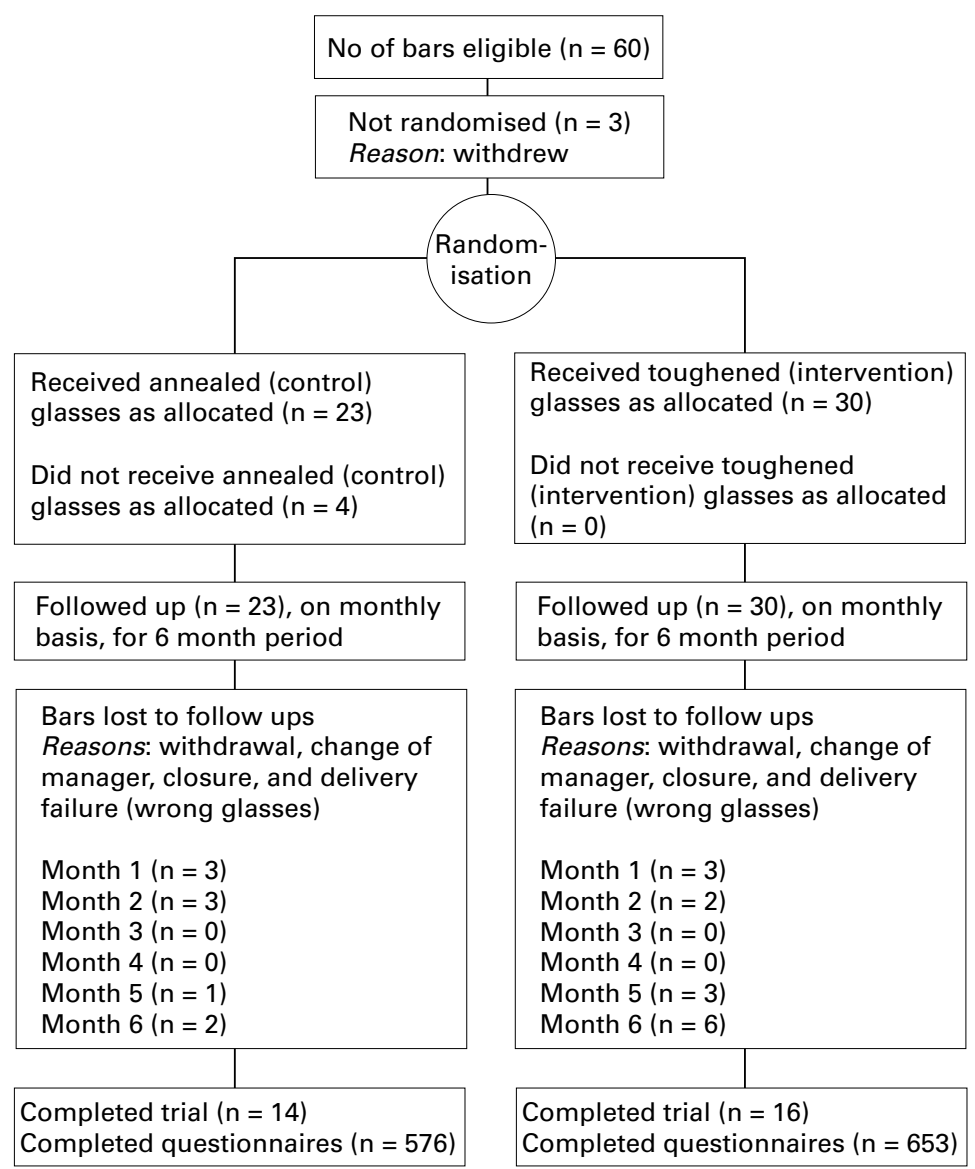

Figure 1 Progress through the various stages of the trial, in terms of bars participating (staff numbers varied on a monthly basis, hence only final numbers are included).

Shepherd $\left.{ }^{9}\right)$. Therefore, the study reported here tested the hypothesis that toughened glassware is safer than annealed glassware in the bar environment.

\section{Methods}

PROTOCOL

From previous data, it was calculated that over a six month period, $26 \%$ of bar workers were injured on one or more occasions with one pint glasses. Thus, a sufficient number of bars to yield 400 bar staff in two groups was required: 200 in a group using only annealed glassware (control group) and 200 in a group using only toughened glassware (intervention group). This assumes a data collection period of six months. For the use of the toughened glass to be worthwhile, the risk needed to be halved so that one in eight or 25 in the intervention group would sustain injury. If a reduction of risk of this size occurs, there is an $80 \%$ chance of detecting it using a statistical test at the conventional (5\%) level. Assuming that on average each bar provided data from four bar staff, a minimum of 100 bars, 50 in each group, were required.

Bars were initially identified from a national database of licensed premises, through trade press listings, and local telephone directories in Cardiff, Gwent, Shropshire, Staffordshire, Stoke-on-Trent, West Midlands, and Bristol. Recruitment was most effective by letter. These letters explained the aims of the trial, and set out the criteria for eligibility. For inclusion, the bar had to satisfy six criteria: (1) be able to use $20 \mathrm{oz}$ government stamped one pint Nonic glasses; (2) be able to use both annealed and toughened glasses (that is no special conditions were attached to their drinks license); (3) cooperate with the researchers by completing monthly questionnaires (all bar staff); (4) not to use any other pint glasses other than those provided during the trial; (5) to have at least four participating bar staff; and (6) to have reported problems with glass related injuries in the previous year.

For those responding to recruitment advertising, a date was arranged for an interview with the bar manager/landlord. At interview, managers/landlords were briefed on the aims of the trial, and their role explained in detail. They then completed an initial structured questionnaire designed to ascertain the extent of glass related injuries and the exact nature and type of bar operated.

Recruitment was continued until the number of eligible bars was sufficient to yield at least 600 members of staff. No record exists of precise numbers of bars approached, but this number exceeded 700 .

\section{ASSIGNMENT}

The unit of randomisation was the bar, as staff numbers were expected to vary. Managers of 53 of the 60 eligible bars agreed to participate in the trial (see fig 1) and these were randomly assigned. The 23 bars in the control group were assigned annealed glassware, and the 30 in the intervention group were assigned toughened glassware. Many types of one pint capacity glass are available, but in this study only the Nonic design was used. Each bar replaced its entire stock of pint glasses with new glasses supplied by the researchers, and throughout the trial only used pint glasses supplied by the researchers. Both types of glass (annealed and intervention) were from the same manufacturer and obtained from the same supplier. It was important to use new glasses because wear and tear is known to decrease impact resistance. ${ }^{10}$

Injuries were recorded using questionnaires distributed monthly via bar managers/ landlords to all staff working in the bar. Precise numbers of questionnaires distributed are not available, but each bar manager/landlord was provided with excess numbers. Thus, response rates of staff are not known precisely.

At the end of the trial, all bar workers were asked to complete an additional questionnaire concerning their opinions of the glasses: their perceptions of durability, strength, and breakage properties.

\section{MASKING}

Neither landlords nor their staffs were informed of the type of glass they were using and neither they nor the researchers knew which of the glasses was more impact resistant (double blinding). Although the packaging did reveal the identity of the glasses, most bar workers were only aware they were testing a "new" type of glass. 
Table 1 Occupational injuries to bar staff caused by one pint glasses

\begin{tabular}{|c|c|c|}
\hline & $\begin{array}{l}\text { Annealed glass } \\
\text { (control group) }\end{array}$ & $\begin{array}{l}\text { Toughened glass } \\
\text { (intervention group) }\end{array}$ \\
\hline No of injuries & 43 & 72 \\
\hline No of people injured & 36 & 62 \\
\hline Total No of people in group & 576 & 653 \\
\hline Total No of hours worked ${ }^{\star}$ & 71738 & 76356 \\
\hline \multicolumn{3}{|c|}{$\begin{array}{l}\text { * Most landlords noted their hours of work as greater than } 80 \text { per week. This was assumed to relate } \\
\text { to hours in the trade, as opposed to hours working the bar. Therefore, exposure times were scaled } \\
\text { down-based on average opening hours, and a six day week. For those not recording their hours } \\
\text { of work, the mean number of hours worked by all "ordinary" bar staff was used. }\end{array}$} \\
\hline \multicolumn{3}{|c|}{ Table 2 Breakdown of injury details by group; results are number (\%) } \\
\hline & $\begin{array}{l}\text { Annealed glass } \\
\text { (control group) }\end{array}$ & $\begin{array}{l}\text { Toughened glass } \\
\text { (intervention group) }\end{array}$ \\
\hline \multicolumn{3}{|l|}{ Site of injury } \\
\hline Hand area (hand, finger, thumb, palm, wrist) & $37(86)$ & $64(89)$ \\
\hline Other & $7(14)$ & $8(11)$ \\
\hline \multicolumn{3}{|l|}{ Place treatment sought } \\
\hline First aid & $32(74)$ & $59(82)$ \\
\hline Other & $11(25)$ & $13(18)$ \\
\hline \multicolumn{3}{|l|}{ Type of treatment required } \\
\hline Other & $33(76)$ & $52(72)$ \\
\hline Sutures & 0 & $4(6)$ \\
\hline None/not recorded & $10(23)$ & $16(22)$ \\
\hline \multicolumn{3}{|l|}{ Effect on lifestyle } \\
\hline Not much & $30(70)$ & $50(69)$ \\
\hline Great effect & $1(2)$ & $8(11)$ \\
\hline
\end{tabular}

Toughened glasses have been reported to disintegrate spontaneously, ${ }^{5}$ and it became evident as the trial progressed that this was a frequent occurrence with the intervention glasses. To attempt to explain this, the impact resistance of the two glass types was assessed using previously described methodology. ${ }^{4}$ New trial glasses, selected at random, were tested in batches of 10 , using a Zwick 5102 pendulum impact tester in a materials laboratory. The test rig was set so that the pendulum struck the glass $1.5 \mathrm{~cm}$ below the rim, at a maximum value of $4 \mathrm{~J}$. For comparison, toughened pint Nonic glasses $(n=10)$ from an alternative manufacturer were also tested.

\section{Results}

Some bars were lost to follow up (see fig 1) and for several reasons, mainly closure. Of those continuing in the trial, landlords were pursued until as many of their staff as possible had completed and returned questionnaires. Some landlords seemed uncertain as to how many staff they employed, and some bar workers either refused to complete the questionnaires, "forgot" to return them, or were unavailable.

A total of 1229 questionnaires were completed and returned by bar staff (782 females and 447 males) over the six month period. The mean age of staff was 32 years, and the mean length of service (in the trial bar) was 49 months.

Ninety eight members of staff experienced 115 injury events (see table 1). Of these, 101 were hand injuries, 91 required first aid in the work place, and four required sutures. The majority of staff injured did not require time off work, and described their injury as only a minor inconvenience. Nine injuries (8\%) affected lifestyle severely, but only three injuries resulted in needing time off work. One injury was reportedly sustained in an assault.
There was no significant difference regarding severity of injury between the two groups (see table 2) except that in the toughened (intervention) group injuries tended to occur simultaneously in more than one body part. This is consistent with injuries caused by glass disintegrating "spontaneously", that is without any specific cause, often leading to wide dispersal of fragments.

\section{ANALYSIS}

Are there significantly fewer injuries in the intervention group, when the number of staff and number of exposure hours are taken into account?

Either the number of bar staff injured or the number of injuries can be analysed, the former being more appropriate, because the statistical model assumes that different responses are independent. Out of 1229 bar staff, 98 experienced one or more injuries, and a total of 115 injury events occurred. Whichever outcome is chosen, an adjustment must be made for either the number of bar staff in the group, or the total number of hours worked over the six month period.

A method to calculate the relative risk (RR) and its confidence interval (CI), must address the proportions (for example 36/576) and event rates (for example 36/71738) in a similar manner. The ratio of number of bar staff injured in the intervention group to number injured in the control group is 1.72 - which can be calculated either as $62 / 36$ or as $0.63 /$ (1-0.63). In the same way, a $95 \%$ CI for this ratio is $0.53 /(1-0.53)$ to $0.72 /(1-0.72)$, that is 1.15 to $2.59 .{ }^{11}$ This appears to indicate that, even at a conservative estimate, there is nearly $15 \%$ greater risk of injury in the intervention group. Adjusting for the number of bar staff gives a final estimated RR of 1.52 (CI 1.01 to 2.28). Alternatively, adjusting for the ratio of the total hours worked gives an estimated RR of 1.62 (CI 1.07 to 2.43). Analysing the total number of injury events (starting with an event ratio of $72 / 115=0.63$, CI 0.54 to 0.71 ) and adjusting for bar staff at risk, gives RR 1.48, and CI 1.02 to 2.15. Alternatively, if the adjustment is for hours worked a RR of 1.57, with CI 1.08 to 2.29 results. This tells us that the injury rate appears to be about $60 \%$ higher in the intervention group. Bearing in mind the limited sample size, the true statistical "disadvantage" of the toughened glass could be just a few per cent more injuries, or could be a doubling or more. However, the CI excludes the null hypothesis that the two glasses are equally safe, that is, there was a difference, significant at $\mathrm{p}<0.05$, in favour of the annealed glass.

IMPACT RESISTANCE

In terms of the energy required to break the glasses, annealed (control) glasses had a higher impact resistance than the intervention glasses, although this was not significant $(p=0.35)$. Three of the intervention glasses remained intact after two attempts, whereas all the annealed glasses were broken. However, in comparison, all toughened Nonics from an alternative source withstood the impact. Mean 
Table 3 Impact resistance of one pint glasses

\begin{tabular}{lllll}
\hline Glass type & Batch size & $\begin{array}{l}\text { Mean (SD) impact } \\
\text { resistance (f) }\end{array}$ & $\begin{array}{l}\text { No intact after } \\
\text { 1st attempt }\end{array}$ & $\begin{array}{l}\text { No intact after } \\
\text { 2nd attempt }\end{array}$ \\
\hline Trial annealed & 10 & $1.77(0.15)$ & 2 & 0 \\
Trial toughened & 10 & $1.38(0.22)$ & 3 & 2 \\
Alternative toughened & 10 & N/A & 10 & 9 \\
\hline
\end{tabular}

$\mathrm{N} / \mathrm{A}=$ not applicable.

impact resistance of the glasses tested is tabulated in table 3 .

Consistent with previous studies, annealed glasses broke into sharp pieces, often leaving the base intact and potentially dangerous, whereas the toughened glass disintegrated into numerous small cuboid fragments with relatively blunt edges.

OPINIONS

All bars in the intervention group reported, at one time or another, that they were having problems with glasses disintegrating spontaneously. Mostly the glasses would disintegrate while on the shelf, but occasionally they were filled and either on the bar or on a table. Forty four per cent of landlords reported that at least one brand of new glass disintegrated as soon as it was taken from the box.

In the intervention group $52 \%$ of staff said the trial glasses were "better" than their previous glasses; 55\% said they were stronger and 60\% said they lasted longer. Forty five per cent reported a problem with the "new" glasses, mostly the tendency of toughened glass to disintegrate spontaneously. In addition, the majority $(63 \%)$ of the breakage of toughened glass occurred while the glass was on the shelf-but not all saw this as a problem per se. Many publicans were willing to accept that toughened glass is safer and causes fewer injuries, although they were often irritated by the inconvenience of clearing many small cubes of glass.

In the control group, $68 \%$ agreed the trial glasses were better and stronger than previous glasses, and $96 \%$ reported no problems. Of interest is that breakage in this group occurred in all locations except on storage shelves.

Staff were reasonably well informed of the characteristics of toughened glass, with $46 \%$ perceiving toughened glass as harder to break; $91 \%$ agreed that toughened glass was a good idea in principle.

\section{Discussion}

This trial is the first to evaluate the effectiveness of "toughened" glass in terms of injury prevention. Previous laboratory research has demonstrated that toughened glassware is more impact resistant and stronger than annealed glassware, ${ }^{4}$ leading to the hypothesis that toughened glass is safer than annealed glass. However, in the trial, the unintentional injury rate due to toughened (intervention) glass was $60 \%$ higher than that due to annealed (control) glass. It had been assumed that the intervention glasses were "toughened" satisfactorily, as they were widely available to the licensed trade, and that precise quality control was exercised during manufacture. However, laboratory testing, performed to explain the frequent failure of the intervention glasses in bars showed that in terms of impact resistance these particular glasses were less tough than annealed glasses. In fact, mean impact resistance was lower for these "toughened" glasses. In comparison, toughened glasses from another manufacturer withstood much greater impact. This shows that although toughened products are widely available, they are toughened to widely differing degrees. Thus if toughened glass is to be marketed as such then standards need to be set to ensure that toughened products are what they claim to be. Glasses should then carry an indication, such as a UK "kite mark", of conformity with manufacturing standards.

There were also problems with the glasses in the intervention group disintegrating spontaneously causing minor superficial injuries. These injuries were caused either when workers were clearing away fragments, and less frequently, by being showered with disintegrating fragments. Consistent with this was that injuries in the intervention group often occurred simultaneously in more than one anatomical region. Furthermore, most of the intervention glasses reportedly disintegrated on the shelf, that is while not in use. By contrast, the annealed glasses failed in day to day usage, for example, during collection and cleaning. Once the problem of spontaneously disintegrating glass has been addressed, by improving standards of toughening, most of these injuries would undoubtedly be prevented.

Those bars that had used toughened products before reported previous experiences of the spontaneous disintegration of glassware, but to a lesser degree. An explanation could be that they were simply more critical and perceptive of the trial glasses. However, it appears that this spontaneous disintegration can occur in new glassware and not just worn glassware, as previously assumed. Bar workers need to be made aware of the potential hazards and both licensed premises workers and customers need to be reassured that one pint capacity glassware conforms to safety standards.

Despite experiencing problems with toughened glass, the majority of staff still agreed that the intervention glasses were "better" than the glassware used previously. Many publicans and their staff accepted that toughened glass is safer and causes fewer injuries, but they were presumably referring to intentional rather than unintentional injuries. Because this study was concerned with unintentional injury and because the "toughened" glassware was in fact less impact resistant than annealed glassware, this study does not contribute evidence of the effectiveness of toughened glass in reducing assault injury. This study therefore highlights the need to educate bar managers/landlords about the differential risk in relation to intentional and unintentional injury. Unfortunately, many staff held unrealistic expectations of toughened glass - that it doesn't break when dropped, or that it is completely harmless when broken. This was well summarised in the words of an experienced female publican: "although the glasses [toughened] were stronger and easier to 
collect, the staff tended to treat them with less care and we tended to have more injuries". Thus, it appears that a proportion of injuries in the intervention group may have been due to staff complacency or carelessness.

In conclusion, this study demonstrates that glass with lower impact resistance caused more injuries, and that "toughened" glassware can have lower impact resistance than annealed glass. It thus emphasises the need for quality control of the toughening process based on published standards that need to be developed as a matter of urgency.

\section{Implications for prevention}

- Increasing the impact resistance of bar glassware reduces the risk of injury.

- The toughening process can increase impact resistance substantially, without altering the dimensions/thickness of glassware, but it can also reduce glass impact resistance.

- Quality control standards are urgently needed to ensure that toughened glass products are what they claim to be.
The authors are grateful to all the publicans and their staff who participated in this trial, and to those who were willing, but not included in the trial. For statistical advice, we acknowledge the help of Dr Robert Newcombe, Department of Medical Statistics, University of Wales College of Medicine, Cardiff. For testing the impact resistance, we thank Dr Mark Waters, Materials Laboratory, Dental School, University of Wales College of Medicine. We also acknowledge the financial support of the PH Trust.

1 Shepherd JP, Shapland M, Pearce NX, et al. Pattern, severity, and aetiology of injuries in victims of assault. $\mathcal{F} R$. Soc Med 1990;83:75-8.

2 Hocking MA. Assaults in South East London. $\mathcal{F}$ R. Soc Med 1989;82:281-4.

3 Shepherd JP, Price M, Shenfine P. Glass abuse and urban Shepherd JP, Price M, Shenfine P. Glass abuse
licensed premises. $\mathcal{F}$. Soc Med 1990;83:276-7.

4 Shepherd JP, Huggett RH, Kidner G. Impact resistance of Shepherd JP, Huggett RH, Kidner G.
bar glasses. F Trauma 1993;35:936-8.

5 Shepherd JP. Preventing injuries from bar glasses. BMF 1994;308:932.

6 Evans DM. Hand injuries due to glass. I Hand Surg 1987;123:284.

7 Shepherd JP, Brickley MR, Gallagher D, et al. Risk of occupational glass injury in bar staff. Injury 1994;25:219-20.

8 McLean W, Shepherd JP, Brann CR, et al. Risks associated with occupational glass injury in bar staff with special consideration of hepatitis B infection. Occup Med 1997;47: 147-50.

9 Shepherd JP. The circumstances and prevention of bar-glass injury. Addiction 1998;93:5-7.

10 Nakamura $H$. Life of tumblers. In: Kunigi M, Tashio M, Saga N, eds. Tenth international congress on glass. Tokyo: Saga N, eds. Tenth international congress
Ceramic Society of Japan, 1974: 42-9.

11 Newcombe RG. Interval estimation for the difference between independent proportions: comparison of eleven methods. Stat Med 1998;17:873-90.

\section{Overprotective parents?}

Regional editor, Ian Scott, discovered a publication from the British Mental Health Foundation in which it is argued that stress in children, such as bed wetting, are in part a reflection of over-protectiveness. The author, Jane McKerrow, states, "children have become closeted by obsessive parents who allow them little chance to take risks and learn from their own mistakes". Compounding this, in a related article in the British newspaper, The Independent, a British sociologist (Frank Ferudi) places much of the blame on an over-zealous child protection industry. "British society behaves as though children were an endangered species. The child safety industry uses every opportunity to promote its central message: that children are permanently at risk from danger. Campaigns centred on a variety of subjects - child abuse, cot death, roving paedophiles, sunbathing - all reinforce the belief that childhood is a particularly dangerous experience".

Editor's comment: If the seemingly foolish premise were well supported scientifically I guess we would have to plead guilty as charged with the mitigating argument that if the worst price we must pay for keeping a child alive and free of major disability is bed wetting, so be it.

\section{Aggressive children}

A report in the Boston Globe cites a study by Field conducted at McDonald's restaurant playgrounds showing that French children acted aggressively $1 \%$ of the time while US children did so $29 \%$ of the time (Dolores Kong, Boston Globe). It raises some fascinating questions about how US boys are raised-for example, lack of touching in infancy, in relation to "the culture of violence". Field is concerned that there may be "even less physical affection toward children in US society as a result of teachers and daycare providers worrying about accusations of sexual abuse. The newspaper report concludes with a quote from Harvard psychologist Dan Kindlon: "We give boys an emotional miseducation. They grow up unable to talk about emotions or to be aware of others' feelings, and they have fewer ways of dealing with stress". 